\title{
Epidemiology, patient profile, and health care resource use for hepatitis $C$ in Italy
}

This article was published in the following Dove Press journal:

ClinicoEconomics and Outcomes Research

10 October 2017

Number of times this article has been viewed

\section{Diego Sangiorgi' \\ Valentina Perrone' \\ Stefano Buda' \\ Lucio Boglione ${ }^{2}$ \\ Giuseppe Cariti ${ }^{2}$ \\ Cinira Lefevre ${ }^{3}$ \\ Carmela Nappi ${ }^{4}$ \\ Luca Degli Esposti'}

'Health, Economics and Outcomes Research, CliCon Srl, Ravenna, Italy; ${ }^{2}$ Unit of Infectious Diseases, Department of Medical Sciences, Amedeo di Savoia Hospital,

University of Turin, Turin, Italy; ${ }^{3}$ Center of Observational Research and Data Sciences, Bristol-Myers Squibb, Rueil-Malmaison, France; ${ }^{4}$ Health Economics, Bristol-Myers Squibb S.r.I., Rome, Italy
Correspondence: Luca Degli Esposti Health, Economics and Outcomes Research, CliCon Srl, Via Salara 36, 48I00 Ravenna, Italy

Tel +3954438393

Fax +39 544.21 2699

Email luca.degliesposti@clicon.it
Objective: The objectives of this study were to estimate the prevalence of Hepatitis $\mathrm{C}$ among six Italian Local Health Units (LHUs), to describe patient and antiviral drug characteristics, and to estimate the health care consumption rates and related costs for the management of patients affected by hepatitis $\mathrm{C}$ virus (HCV) infection by using data from routine clinical practice.

Methods: We conducted a retrospective study using administrative databases of six Italian LHUs. All patients who had a record related to HCV during the enrollment period (July 1, 2009, to December 31, 2014) and who had at least 6 months of data available prior to the first HCV record were included. The date of the first record related to HCV during the enrollment period was considered as a proxy of diagnosis and used as the index date. Patients were followed from the index date up to 1 year, death, or exiting the database. Using the overall cohort of HCV adult patients as the numerator, we estimated the prevalence of HCV among six LHUs. The denominators were obtained from the National Institute of Statistics $(\mathrm{N}=1,665,682)$. We also evaluated descriptive patient's characteristics and treatment patterns, and estimated health care consumption rates and related costs for the management of the HCV patients.

Results: A total of 7,550 patients were analyzed, of whom $57 \%$ were male with a mean age of $57.6 \pm 16.4$ years. The prevalence of HCV was estimated to be $0.45 \%$ ( $95 \%$ confidence interval $0.44-0.46$ ). During the follow-up period, $78.6 \%$ of $\mathrm{HCV}$ patients had received no antiviral treatment. The annual health care cost associated with HCV infection was $€ 6,022.7( \pm 7,922.6)$ while the cost specific to HCV care was $€ 3,154.6( \pm 4,972.0)$

Conclusion: Our findings showed that, in the Italian real-world setting, only a small proportion of HCV-infected patients received an antiviral treatment. Despite the current low prevalence of $\mathrm{HCV}$, the economic impact of such disease remains high.

Keywords: hepatitis $\mathrm{C}$ virus infection, prevalence, antiviral drug, health care resources use, real-world data

\section{Introduction}

Hepatitis $\mathrm{C}$ is an infectious disease caused by the hepatitis $\mathrm{C}$ virus (HCV), and it is one of the major global causes of death and morbidity. ${ }^{1,2}$ The true incidence of HCV on a global scale is not well known, because acute infection is generally asymptomatic. The most recent estimates of disease burden show an increase in seroprevalence over the last 15 years to $2.8 \%$, equating to $>185$ million infections worldwide. ${ }^{1,3}$ However, $\mathrm{HCV}$ prevalence is highly variable worldwide. ${ }^{2,4}$ A recent European review has estimated that the prevalence of $\mathrm{HCV}$ varies between $2.4 \%$ for Western and Central Europe and $2.9 \%$ for Eastern Europe. ${ }^{5}$

At present, few data are available on the epidemiology of $\mathrm{HCV}$ infections considering the Italian general population. ${ }^{6-12}$ In addition, the few Italian studies available 
were obtained in limited geographic areas and were not representative of the whole Italian population. ${ }^{11}$ The limited evidence shows that prevalence of HCV seropositivity was higher in Southern (7.3\%) and Insular areas than in Central (6.1\%) and Northern regions (about 1.6\%). ${ }^{7}$

Approximately $55 \%-85 \%$ of individuals exposed to $\mathrm{HCV}$ develop chronic infection. ${ }^{2}$ Overall, $30 \%$ of the patients chronically infected may progress to cirrhosis in their lifetime, whereas $3 \%-8 \%$ of cirrhotic patients may develop hepatocellular carcinoma (HCC) every year. ${ }^{1}$ According to the study conducted by the European Centre for Disease Prevention and Control (ECDC), Italy, has the highest number of HCV-positive subjects in Europe and the highest death rate from $\mathrm{HCC}$ and cirrhosis. ${ }^{4}$

The therapies available to treat HCV have considerably changed over the last 5 years and completely changed the disease landscape. Until mid-2013, peg-interferon (pegIFN) alfa in combination with ribavirin (RBV) was the only treatment option for chronic HCV infection in Italy. In April 2013, the first generation of direct-acting antivirals (DAAs) became available in Italy, which were two protease inhibitors (PIs) (boceprevir and telaprevir) for the management of $\mathrm{HCV}$ in combination with peg-IFN-alfa and RBV. ${ }^{13,14}$ And more recently, in 2016, many new HCV DAAs (such as sofosbuvir, simeprevir, daclatasvir, ombitasvir, paritaprevir, ledipasvir) have been licensed in Europe, for use as part of combination therapies for HCV management, and have shown cure rates above $90 \%$ as reported by SmPCs, respectively. ${ }^{15}$

Despite the strong recommendation for treatment for nearly all HCV-infected patients, a large percentage of infected individuals remain undiagnosed and untreated for a considerable period of time, putting them at risk of advanced liver disease. ${ }^{16}$

The management of HCV infection generates a considerable economic burden on National Health Service (NHS) in Italy, ${ }^{17}$ and the overall health care resource utilization associated with HCV tends to increase with advanced disease states (ie, compensated cirrhosis, decompensated cirrhosis, and HCC). ${ }^{9}{ }^{17}$

The objectives of this study were 1) to estimate the prevalence of HCV among six Italian Local Health Units (LHUs), 2) to describe patient and antiviral drug characteristics, 3) to estimate the health care resources consumption for management of the patients affected by HCV infection using data from routine clinical practice.

\section{Methods}

\section{Data source}

The study was conducted using administrative databases of six LHUs (Torino, Piemonte; Treviso, Veneto; Grosseto,
Toscana; Terni, Umbria; Barletta-Andria-Trani, Puglia; and Cosenza, Calabria) geographically distributed throughout the national territory. ${ }^{18}$

The databases used were 1) the Health-Assisted Subjects' Database, containing patients' demographic data; 2) the Outpatients and Inpatients Pharmaceutical Database, providing information for each medication prescription; all drugs prescribed were classified according to the international Anatomic Therapeutic Classification system (ATC codes); 3) the Hospital Discharge Database, including all hospitalization data, with the main and secondary discharge diagnosis codes classified according to the International Classification of Diseases, Ninth Revision, Clinical Modification (ICD-9-CM) and Diagnosis-Related Group (DRG) reimbursement rate; 4) the diagnostic tests and specialist visits database, which includes all information about outpatient specialist services and the clinical laboratory database.

The patient code in each database allowed electronic linkage across all databases. Informed consent is not required for using encrypted retrospective information. This study was approved by the local ethics committee in each participating LHU according to the Italian law regarding the conduct of observational analysis. ${ }^{19}$

\section{Study design and cohort definition}

This study was a retrospective cohort study from January 1, 2009 to December 31, 2015 (study period) that included all beneficiaries aged $\geq 18$ years of each LHU with a record related to $\mathrm{HCV}$ (ie, positive $\mathrm{HCV}$ testing or medications for HCV) retrieved between July 1, 2009 and December 31, 2014 (enrollment period) and who had at least 6 months of data available prior to the first HCV record.

The date of the first record related to $\mathrm{HCV}$ (ie, positive $\mathrm{HCV}$ testing or medications for HCV or hospital admissions for $\mathrm{HCV}$ complications) during the enrollment period was considered as a proxy of diagnosis and used as the index date. Patients were followed up from the index date up to 1 year, death, or exiting the database, whatever occurred first (follow-up period). The clinical characteristics of patients enrolled in this study were investigated during 6 months prior to the index date (characterization period).

\section{Study variables}

Data on baseline characteristics, including demographics (age and gender), medical history (hospital admission, prescribed HCV drugs, and profile of comorbidity) were collected during the characterization period. The HCV treatments of interest 
were all IFN-based combinations (ATC code: L03AB) and protease inhibitor (PI) combinations with or without IFN (boceprevir [ATC code: J05AE12] and telaprevir [ATC code: J05AE11]). Cirrhosis and HCC were identified as the presence of hospitalizations for cirrhosis or HCC related ([ICD-9 CM code: 571.XX] and [ICD-9 CM code: 155.XX], respectively) during the characterization period. Liver transplantation was identified by the presence of hospitalization with ICD-9-CM code: 50.5 (liver transplant ICD-9-CM procedure code) during the characterization period. The coinfection with human immunodeficiency virus (HIV) was identified by the presence of DRG codes: 488-489-490, or HIV related hospitalization (ICD-9 CM code: 042.XX) or by use of combined antiretroviral agents (ATC code: J05A). Finally, hepatitis B virus (HBV) was identified as the presence of $\mathrm{HBV}$ related hospitalization (ICD-9 CM codes: 070.2X, 070.3X).

Previous use of dermatological (ATC code: D) and antianemic drugs (ATC code: B03) was evaluated. The patients were also characterized based on hospitalization for cardiovascular reasons (ICD-9-CM codes: 410-414) and neuropsychological events (ICD-9-CM codes: 290-319). Comorbidities were measured using the Charlson Comorbidity Index $(\mathrm{CCI})^{20}$ that assigns a score to each concomitant disease identified through treatments and hospitalizations during the characterization period; the CCI score reflects a patient's overall health status. This same methodology has been widely used as a way to compare disease severity in observational retrospective studies when data are unavailable. ${ }^{21}$

During the follow-up period, the presence of HCV treatments (peg-IFN-based combinations or PI combinations with or without IFN) were evaluated. Patients were considered treated if they had at least one prescription of HCV drugs (only the first $\mathrm{HCV}$ medication prescribed was considered in this analysis).

In order to estimate $\mathrm{HCV}$ management costs, we estimated the overall consumption of health care resources in the 12 months after the index date (follow-up period). The health care consumptions for hospitalizations, drug treatments, and outpatient specialist services were classified as related and not related to the disease analysis. The health care consumption rates specifically related to $\mathrm{HCV}$ were also estimated; these were evaluated as the percentage of patients with at least $\mathrm{HCV}$ treatments, $\mathrm{HCV}$ test, or hospitalization related to $\mathrm{HCV}$ during the follow-up period.

\section{Statistical analysis}

Using the overall cohort of HCV adult patients as the numerator, we estimated the prevalence of HCV among six LHUs included in the study. The denominators were obtained from the National Institute of Statistics, ${ }^{36}$ comprised the demographic distribution by gender and age of the population which were extracted from the LHUs). In particular, since the NHS website provides only information about the total number of assisted subjects by each LHU, to obtain the distribution according to gender and age, we reweighted this number according to the population distribution available on the National Institute of Statistics website.

We calculated descriptive statistics of the variables of interest by reporting means and standard deviations (mean \pm SD) for continuous variables; whereas categorical variables were expressed as numbers and percentages. A confidence interval (CI) for an effect size, with a $95 \%$ level of confidence was reported. All analyses were performed using STATA software version 12.1 (Stata Corp LP, College Station, TX, USA).

\section{Cost analysis}

The mean annual health care costs per patient, for the management of the $\mathrm{HCV}$ infection, based on the total resource consumption were assessed during the follow-up period. The total resource consumption was defined by the sum of all: prescribed treatments, outpatient specialist services, and hospital admission. Both the overall and specific costs related to $\mathrm{HCV}$ annualized health care resources were estimated. The cost analysis was conducted from the perspective of the Italian NHS. The costs are reported in euros $(€)$. Drug costs were evaluated using the Italian NHS purchase price. Hospitalization costs were determined by using the DRG tariff. The cost of instrumental and laboratory tests was defined according to the tariffs applied by regions.

\section{Results}

During the study enrollment period (2009-2014), we identified 7,550 patients with a diagnosis of HCV; of whom $57 \%$ were male with a mean age of $57.6 \pm 16.4$ years. Figure 1 shows the details of the inclusion and exclusion criteria of the study.

$\mathrm{HCV}$ prevalence in the study population was estimated at $0.45 \%$ (95\% CI 0.44-0.46) (denominator was $\mathrm{N}=1,665,682$ ). The geographic distribution of HCV prevalence, among the three macro-areas studied, was: $0.26 \%$ in Northern Italy, $0.49 \%$ in Central Italy, and $0.51 \%$ in Southern Italy. The prevalence of $\mathrm{HCV}$ at study enrollment tended to be higher in males $0.53 \%(95 \%$ CI $0.51-0.55)$ than females $0.38 \%$ (95\% CI $0.37-0.39$ ). The peak was in middle-age and older individuals $(0.56 \%$ [95\% CI $0.54-0.58$ ] and $0.67 \%$ [95\% CI $0.65-0.70]$ in the 50-60 and 70+ years age group, 


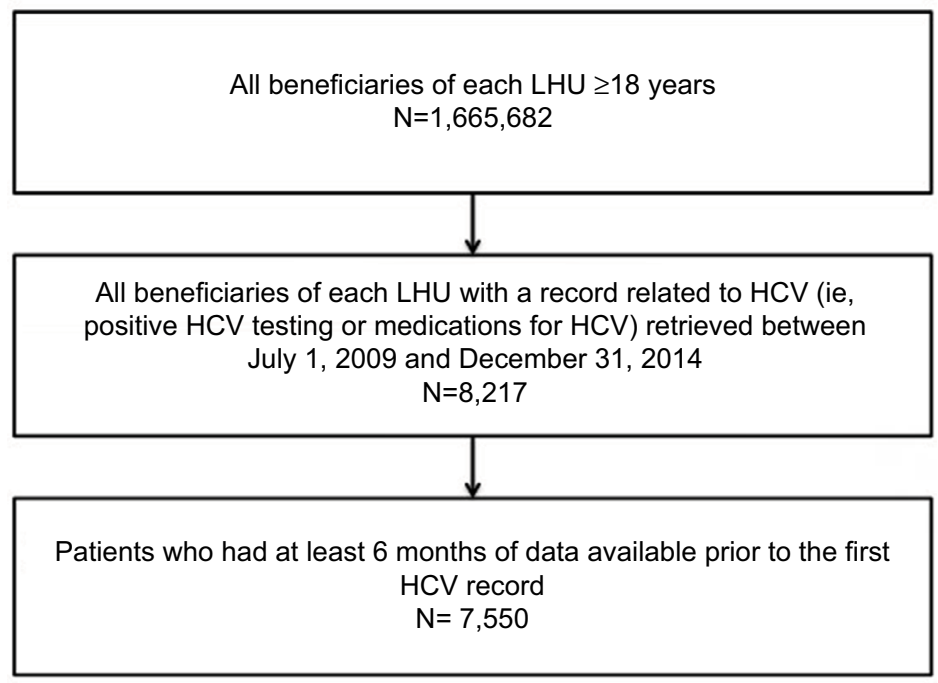

Figure I Flowchart of cohort definition

Abbreviations: HCV, hepatitis C virus; LHU, local health unit.

respectively); while, among those aged 18-29 and 30-49 years it was $0.13 \%(95 \%$ CI $0.12-0.14)$ and $0.39 \%(95 \%$ CI $0.37-0.41)$, respectively. Patient characteristics and prior health care resource utilization are summarized in Table 1. Mean (SD) patient age at the index date was 57.6 (16.4) years. Among patients with HCV, most of them are 50-69 years (37.7\% of all subjects included) followed by $30-49$ years age group (30.5\% of all subjects included).

More than half of patients had one or more comorbidity at baseline; the mean (SD) CCI was 1.1 (1.4). Patients affected by HIV and/or HBV were about $1 \%$. Patients affected by anemia and dermatologic events were $5.1 \%$ and $2.5 \%$, respectively, and $8 \%$ had cirrhosis, while about $1 \%$ had HCC (Table 1). Four patients $(0.1 \%)$ reported liver transplantation for $\mathrm{HCV}$ at baseline. Ninety-six percent $(n=7,247)$ of patients had not received any antiviral treatment during 6 months pre-index date.

The distribution of patients affected by HCV treated and untreated during the follow-up period is shown in Figure 2 . The majority of HCV patients ( $\mathrm{n}=5,934 ; 78.6 \%$ of all patients included) had received no antiviral treatment during the follow-up period. Among treated patients ( $\mathrm{n}=1,616 ; 21.4 \%$ of all subjects included), 1,556 patients were treated with peg-IFN (with or without RBV) and 30 patients received PI. Prescriptions for both peg-IFN and PI were given to $2 \%$ of treated patients. During the overall follow-up period, $\sim 42 \%$ and $46 \%$ of patients had at least one hospitalization and diagnostic HCV-related test, respectively; while, during the same period, $49 \%$ and $70 \%$ of patients had at least one hospitalization and diagnostic test per any cause, respectively.
Table I Baseline demographic and clinical characteristics of the study population $(\mathrm{N}=7,550)$

\begin{tabular}{ll}
\hline Characteristics & \\
\hline Age (years) & \\
Mean \pm SD & $57.6 \pm 16.4$ \\
I8-29 & $335(4.4)$ \\
$30-49$ & $2,307(30.5)$ \\
$50-69$ & $2,846(37.7)$ \\
$70+$ & $2,062(27.3)$ \\
Gender & \\
Male & $4,308(57.1)$ \\
Charlson comorbidity index, mean (SD) & $1.1 \pm 1.4$ \\
0 & $3,218(42.6)$ \\
I-2 & $3,364(44.5)$ \\
$3-4$ & $749(9.9)$ \\
$5+$ & $219(2.9)$ \\
Coinfections with HBV or HIV & $88(1.2)$ \\
HIV & $33(0.4)$ \\
HBV & $55(0.7)$ \\
History of hospitalization & \\
Cardiovascular events & $9(0.1)$ \\
Cirrhosis & $612(8.1)$ \\
HCC & $52(0.7)$ \\
Liver transplantation & $4(0.1)$ \\
Neuropsychological events & $8(0.1)$ \\
HCV treatment type during 6 months pre-ID & \\
peg-IFN with or without RBV & $289(3.8)$ \\
PI with or without peg-IFN & $14(0.2)$ \\
Untreated patients & $7,247(96.0)$ \\
Other treatments & \\
Antianemic drugs & $385(5.1)$ \\
Dermatological drugs & $185(2.5)$ \\
\hline
\end{tabular}

Note: Data shown as $n(\%)$ or mean \pm SD.

Abbreviations: SD, standard deviation; HCV, hepatitis C virus; HIV, human immunodeficiency virus; $\mathrm{HCC}$, hepatocellular carcinoma; HBV, hepatitis $B$ virus; peg-IFN, peg-interferon; RBV, ribavirin; PI, protease inhibitors; ID, index date. 


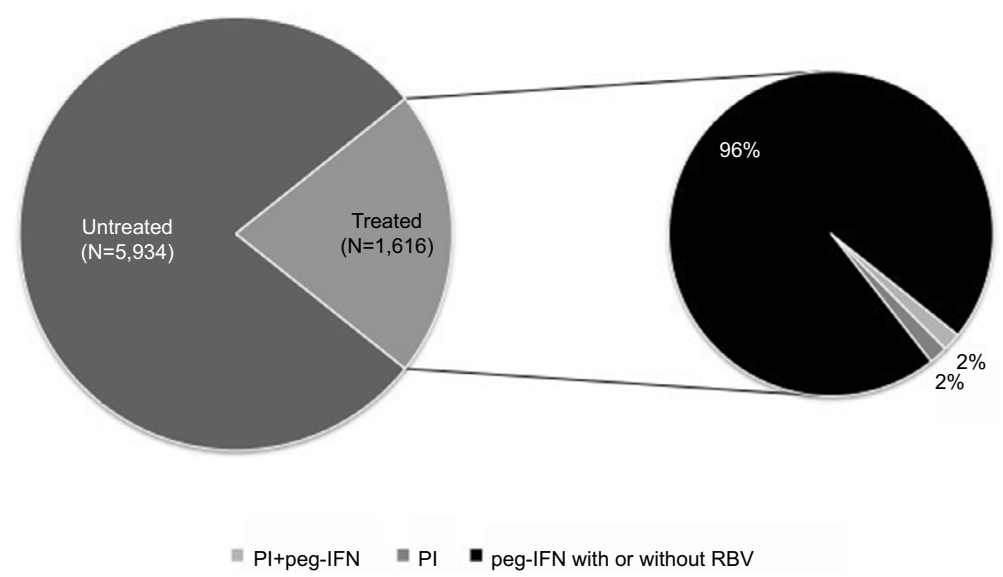

Figure 2 Treatment patterns during the follow-up period

Abbreviations: peg-IFN, peg-interferon; RBV, ribavirin; PI, protease inhibitors.

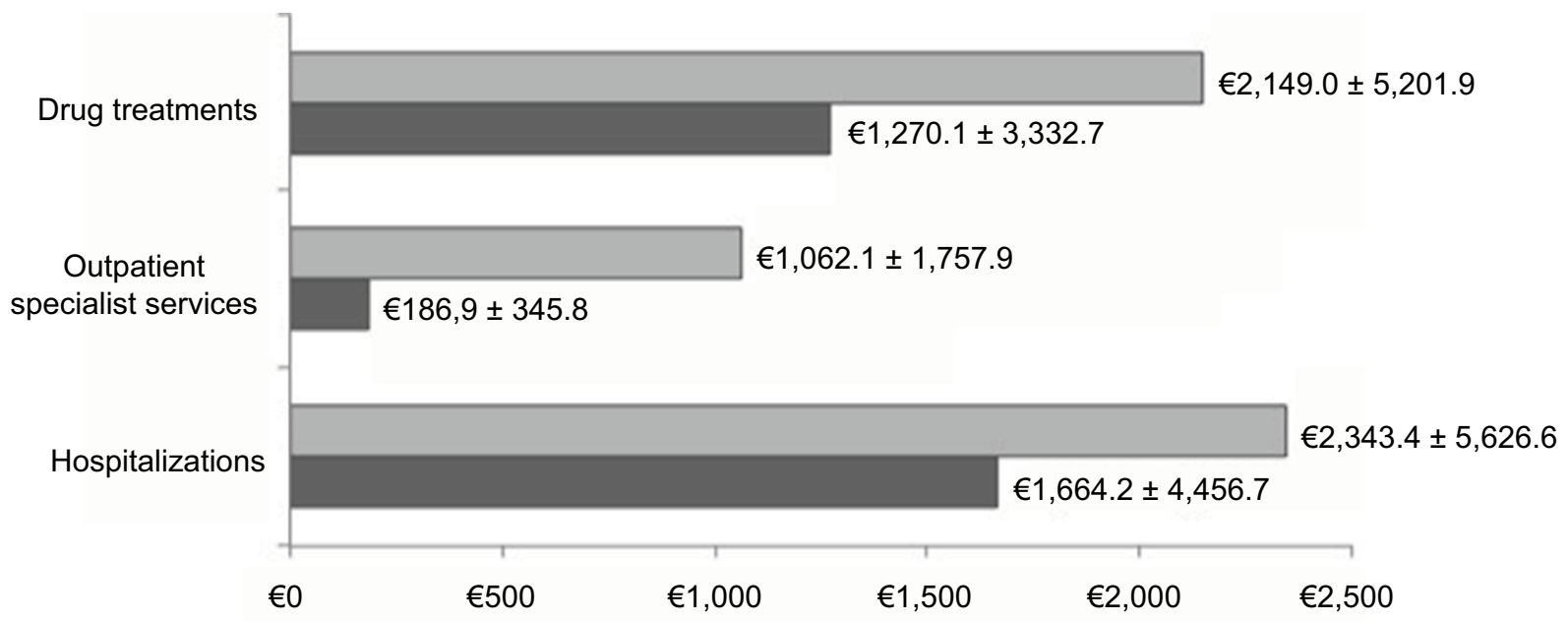

Overall health care consumption

Specifically related to HCV health care consumption

Figure 3 Annual health care costs (mean \pm standard deviation) for the management of HCV patients, based on resource consumption during the follow-up period Abbreviation: HCV, hepatitis C virus

Annual health care costs for the management of HCV patients, based on resource consumption from index date, are reported in Figure 3. The overall annual expenditure for the management of $\mathrm{HCV}$ was $€ 6,022.7( \pm 7,922.6)$ per patient, of which $€ 2,149.0( \pm 5,201.9)$ was for drug treatment, $€ 2,343.4$ $( \pm 5,626.6)$ for hospitalizations, and $€ 1,062.1( \pm 1,757.9)$ for outpatient specialist services. The health care consumption directly related to $\mathrm{HCV}$ health care is also reported in Figure 3. The mean annual cost of hepatitis C-related care per patients was $€ 3,154.6( \pm 4,972.0)$.

\section{Discussion}

$\mathrm{HCV}$ infection constitutes an important worldwide public health problem that is associated with a substantial socioeconomic burden. ${ }^{2,4,22}$ Available data indicate that infection with $\mathrm{HCV}$ varies considerably by country and region. ${ }^{4}$
Nevertheless, the true burden of the disease is not well known in many countries, given that $\mathrm{HCV}$ testing is not routinely done, and the diagnosis often occurs several years after the initial infection. Despite the high costs of untreated hepatitis $\mathrm{C}$ patients, the hepatitis C-related reduction in quality of life, a majority of patients with chronic hepatitis $\mathrm{C}$ are currently untreated in many European countries. ${ }^{23}$

Our analysis estimated that the prevalence of confirmed HCV infection among six LHUs analyzed in the years 20092014 was $0.45 / 1,665,682$ health-assisted individuals. Our data differ from those observed in the earlier studies, ${ }^{3,6-8,11,37,38}$ most likely because of the difference in the study design and the difference in data sources. Unfortunately, these are mainly estimates and not collected data. In addition, $\mathrm{HCV}$ prevalence is probably underestimated because this infection is mostly asymptomatic in the acute phase. Although the prevalence of 
$\mathrm{HCV}$ in Italy is unknown, ${ }^{11}$ an active surveillance program for symptomatic acute hepatitis cases has reported a rate of $0.2 / 100,000$ inhabitants in $2015 .{ }^{10}$ Our findings are in line with a recently published nationwide study, which used the same methods of analysis as ours in a real-world clinical setting. The study conducted by Perrone et al, ${ }^{12}$ from 2009 to 2010 , showed that the prevalence of HCV among $\sim 2.5$ million health-assisted individuals was $0.4 \%$. The recent study conducted by Lapi et al, analyzing all outpatients aged at least 15 years registered in the Italian Health Search IMS Health Longitudinal Patient Database from January 1, 2002 to June 30, 2013 reported that the prevalence rate of HCV in the 11 -year study period was in the range from $0.24 \%$ to $0.50 \%{ }^{24}$

The epidemiological status of HCV infection among the European countries is continuously changing and may vary region by region. According to the recent systematic review, ${ }^{25}$ in Europe, the HCV prevalence is estimated at 1.7\% showing a decrease from that previously reported. The lowest prevalence $(0.9 \%)$ is reported from Western Europe and the highest (3.1\%) from Central Europe.

The results of our analysis also showed that the HCV prevalence appears to increase with age; this trend is in accordance with what has already been reported previously in Italian studies. ${ }^{11}$ As expected, the current descriptive data suggest that patients with $\mathrm{HCV}$ infection at younger age are less likely to have chronic hepatitis $\mathrm{C}$ than those infected at older ages. ${ }^{26-28}$

Although the incidence and spread of infection have decreased over the last decade both in Italy and in the rest of the world, past infection remains a major health problem in terms of incidence of terminal liver diseases that arise many years after infection. A large proportion of $\mathrm{HCV}$ infected persons develop chronic $\mathrm{HCV}$ infection and are at risk for advanced liver fibrosis, HCV-related extra-hepatic complications, cirrhosis, and HCC. The progression to cirrhosis is often clinically silent, and some patients are not known to have hepatitis $\mathrm{C}$ until they present with the complications of end-stage liver disease or HCC. Our findings have shown that $8 \%$ and about $1 \%$ of $\mathrm{HCV}$-infected patients had cirrhosis and $\mathrm{HCC}$ at baseline, respectively.

Many published studies found that approximately from 5\% to $20 \%$ of persons infected with hepatitis C, if not treated, will develop cirrhosis within 20 years. ${ }^{2,29}$ Other existing literature has assessed factors associated with treatment ineligibility in the era of interferon-based HCV therapy. ${ }^{30}$ Particularly, financial, logistical, patient-provided relationships and disease problems as well as patient-specific variables (ie, comorbidities, advanced age) all contribute to these low treatment rates.

In this real-world assessment, $78.6 \%$ of individuals with confirmed $\mathrm{HCV}$ infection have not received antiviral treat- ment. This high proportion of untreated patients could be explained by the expected important adverse events and poor manageability of the therapies available at the time of the study, as well as the fact that physicians/patients were waiting for the new generation of the antivirals to arrive in the Italian market. At any rate, our findings are consistent with those of other Italian studies under real-world circumstances, in the literature so far. ${ }^{12,31}$ Stroffolini et al showed that only $33 \%$ of evaluated $\mathrm{HCV}$-infected patients were treated with current standard of care for hepatitis C. ${ }^{31}$ A recent retrospective Italian study revealed that ${ }^{12}$ patients who have not received $\mathrm{HCV}$ treatments showed a higher rate of progression of disease than patients who underwent therapy; in addition, these results also showed that patients receiving no treatment led to an increase in health care resources, especially in terms of hospitalizations. Providing early appropriate therapeutic interventions that can prevent liver disease progression related to $\mathrm{HCV}$ can potentially further reduce the economic burden associated with chronic hepatitis infection. ${ }^{32,33}$

However, the true economic burden of the disease is not well known in many countries, because capacity is limited for collecting epidemiologic data and it is still reported with no information about actual costs incurred by HCV patients. ${ }^{9,11,34}$ Our cost analysis suggests that, in an Italian health care setting, the total health care cost associated with $\mathrm{HCV}$ infection was $€ 6,022.7( \pm 7,922.6)$ per patient while the cost specific to care $\mathrm{HCV}$ was $€ 3,154.6( \pm 4,972.0)$ per patient.

A recent review of Marcellusi et $\mathrm{al}^{17}$ reported that the total economic burden associated with $\mathrm{HCV}$-induced diseases was estimated at $€ 1.06$ billion (95\% CI $€ 0.61-€ 1.63$ ); a percentage of $60.6 \%$ was associated with indirect costs and $39.4 \%$ with direct costs. The differences versus published data were possibly due to the different health care settings (type of health care coverage), value of reimbursement for hospitalizations, drug prices, and analysis perspective. ${ }^{35}$

Our cohort of patients reflected real clinical practice, and the results must be interpreted, taking into account limitations related to the observational nature of the study, based on data collected through administrative databases. As a consequence, we cannot therefore exclude the possibility that we may have underestimated the prevalence of HCV. Since the information concerning the comorbidities and the information relative to the severity of the pathology are not available, a proxy of the comorbidities was used, considering the use of specific drugs, hospitalizations, exemptions, which could implicate an underestimation of such conditions in our study. In addition, the problem of underestimation within the prevalence rates of $\mathrm{HCV}$, cirrhosis, $\mathrm{HCC}$, and liver transplantation could be regarding the different 
identification schemes. The use of DRG or ICD-9 or use of medication versus ICD-9 alone may lead to different outcomes. No information on the reasons for no-treatment was included because the data were not retrievable from the data set given their administrative scope. Another limitation is represented by the short observational period; for the evaluation of outcomes of interest, it would be desirable to have a longer time interval and a larger number of patients. The results and conclusions of this study are limited to the population analyzed.

\section{Conclusion}

This study shows that, in the Italian real-world setting, only a small proportion of $\mathrm{HCV}$-infected patients received an antiviral treatment. Despite the current low prevalence of $\mathrm{HCV}$, the economic impact of the disease remains high. Future research should focus on a larger number of LHUs and cover a longer follow-up period, to ensure national representativity and include recently launched HCV treatments.

\section{Disclosure}

Cinira Lefevre is an employee of Bristol-Myers Squibb (France) and Carmela Nappi is an employee of Bristol-Myers Squibb S.r.l. (Italy). The authors report no other conflicts of interest in this work.

\section{References}

1. World Health Organization (WHO). Guidelines for the screening, care and treatment of persons with chronic hepatitis $\mathrm{C}$ infection. Updated version, April 2016. Available from: http://apps.who.int/iris/bitstr eam/10665/205035/1/9789241549615_eng.pdf?ua=1. Accessed July 4, 2017.

2. World Health Organization. Hepatitis C [updated July 2016]. Available from: http://www.who.int/mediacentre/factsheets/fs164/en/. Accessed July 4, 2017.

3. Petruzziello A, Marigliano S, Loquercio G, Cozzolino A, Cacciapuoti C. Global epidemiology of hepatitis $\mathrm{C}$ virus infection: an up-date of the distribution and circulation of hepatitis $\mathrm{C}$ virus genotypes. World $J$ Gastroenterol. 2016;22:7824.

4. European Centre for Disease Prevention and Control. Technical report hepatitis $\mathrm{B}$ and $\mathrm{C}$ in the EU neighborhood: prevalence, burden of disease and screening policies; 2010. Available from: http://www.ecdc.europa. eu/en/publications/Publications/TER_100914_Hep_B_C\%20_EU_ neighbourhood.pdf. Accessed October 10, 2016.

5. Mohd Hanafiah K, Groeger J, Flaxman AD, Wiersma ST. Global epidemiology of hepatitis $C$ virus infection: new estimates of age-specific antibody to HCV seroprevalence. Hepatology. 2013;57:1333-1342.

6. Mele A, Tosti ME, Spada E, Mariano A, Bianco E; SEIEVA Collaborative Group. Epidemiology of Acute Viral Hepatitis: Twenty Years of Surveillance through SEIEVA in Italy and a Review of the Literature. Rome: Istituto Superiore di Sanità (Rapporti Istisan 06/12); 2012.

7. Marascio N, Liberto MC, Barreca GS, et al. Update on epidemiology of HCV in Italy: focus on the Calabria Region. BMC Infect Dis. 2014;14(Suppl 5):S2.

8. Torre GL, Gualano MR, Semyonov L, Nicolotti N, Ricciardi W, Boccia A. Hepatitis C virus infection trends in Italy, 1996-2006. Hepat Mon. 2011;11:895-900.
9. Mennini FS, Marcellusi A, Andreoni M, Gasbarrini A, Salomone S, Craxì A. Health policy model: long-term predictive results associated with the management of hepatitis $\mathrm{C}$ virus-induced diseases in Italy. Clin Outcomes Res. 2014;6:303-310.

10. ISS (Istituto Superiore di Sanità) and SEIEVA (Sistema Epidemiologico Integrato dell'Epatite Virale Acuta) Collaborative Group. Epidemiology of acute viral hepatitis in Italy: results of the surveillance through SEIEVA. Annual Report Rome; 2015. Available from: http://www.iss. it/binary/seie/cont/Tassi_EpatiteC_2015.pdf. Accessed July 4, 2017.

11. Fondazione Italiana per la Ricerca in Epatologia. Libro Bianco AISF 2011; Proposta per un piano nazionale per il controllo delle malattie epatiche; definizione ambiti e possibili interveti [White Book of AISF; Proposal of a national plan for the control of hepatic diseases; definition of scopes and possible interventions. 2011. [Accessed May 13, 2014]. Available from: http://www.webaisf.org/media/13891/libro-biancoaisf-2011.pdf. Accessed May 13, 2014. Italian.

12. Perrone V, Sangiorgi D, Buda S, Degli Esposti L. Disease progression and health care resource consumption in patients affected by hepatitis C virus in real practice setting. Clin Outcomes Res. 2016;8:591-597.

13. Foote BS, Spooner LM, Belliveau PP. Boceprevir: a protease inhibitor for the treatment of chronic hepatitis C. Ann Pharmacother. 2011;45:1085-1093.

14. Smith LS, Nelson M, Naik S, Woten J. Telaprevir: an NS3/4A protease inhibitor for the treatment of chronic hepatitis C. Ann Pharmacother. 2011;45:639-648.

15. European Medicines Agency. European public assessment reports. [webpage on the Internet]. Available http://www.ema.europa.eu/ ema/index.jsp?curl=pages/medicines/landing/epar_search.jsp\&mid= WC0b01ac058001d124. Accessed July 4, 2017.

16. Mah'moud MA. Current management of hepatitis $\mathrm{C}$ virus infection. N C Med J. 2016;77:188-193.

17. Marcellusi A, Viti R, Capone A, Mennini FS. The economic burden of HCV-induced diseases in Italy. A probabilistic cost of illness model. Eur Rev Med Pharmacol Sci. 2015;19:1610-1620.

18. Demo Istat. Istat; Istituto nazionale di statistica. [National institute of statistics]. Available at: http://demo.istat.it/pop2016/index.html. Accessed July 4, 2017. Italian.

19. AIFA Guideline for the classification and conduction of the observational studies on medicines. Available from: https://www.agenziafarmaco.gov. it/ricclin/sites/default/files/files_wysiwyg/files/CIRCULARS/Circular\%2031st\%20May\%202010.pdf. Accessed July 4, 2017.

20. Gonnella JS, Daniel L, Gozum MV, Callahan CA, Barnes CA. Disease Staging Clinical and Coded Criteria. Version 5.26. Ann Arbor, MI: Thomson Medstat; 2010.

21. Fadini GP, Avogaro A, Degli Esposti L, et al. Risk of hospitalization for heart failure in patients with type 2 diabetes newly treated with DPP-4 inhibitors or other oral glucose-lowering medications: a retrospective registry study on 127,555 patients from the Nationwide OsMed HealthDB Database. Eur Heart J. 2015;36:2454-2462.

22. Dultz G, Zeuzem S. Hepatitis C virus. Gastroenterol Clin North Am. 2015;44:807-824.

23. Papatheodoridis GV, Tsochatzis E, Hardtke S, Wedemeyer H. Barriers to care and treatment for patients with chronic viral hepatitis in Europe: a systematic review. Liver Int. 2014;34:1452-1463.

24. Lapi F, Capogrosso Sansone A, Mantarro S, et al. Hepatitis C virus infection: opportunities for an earlier detection in primary care. Eur $J$ Gastroenterol Hepatol. 2017;29(3):271-276.

25. Petruzziello A, Marigliano S, Loquercio G, Cacciapuoti C. Hepatitis $\mathrm{C}$ virus (HCV) genotypes distribution: an epidemiological up-date in Europe. Infect Agent Cancer. 2016;11:53.

26. Bellentani S, Tiribelli C. The spectrum of liver disease in the general population: lesson from the Dionysos study. J Hepatol. 2001;35: 531-537.

27. Ascione A, Tartaglione T, Di Costanzo G. Natural history of chronic hepatitis C virus infection. Dig Liver Dis. 2007;39(Suppl 1):S4-S7.

28. Chen SL, Morgan TR. The natural history of hepatitis C virus (HCV) infection. Int J Med Sci. 2006;3(2):47-52. 
29. University of Washington. Hepatits C Online - HCV Epidemiology in the United States. Updated version; February 2017. Available from: http://www.hepatitisc.uw.edu/pdf/screening-diagnosis/epidemiologyus/core-concept/all. Accessed July 4, 2017.

30. Rogal SS, Arnold RM, Chapko M, et al. The patient-provider relationship is associated with hepatitis C treatment eligibility: a prospective mixed-methods cohort study. PLoS One. 2016;11:e0148596.

31. Stroffolini T, Spadaro A, Di Marco V, et al. Current practice of chronic hepatitis B treatment in Southern Italy. Eur J Intern Med. 2012;23:e124-e127.

32. Razavi H, Elkhoury AC, Elbasha E, et al. Chronic hepatitis C virus (HCV) disease burden and cost in the United States. Hepatology. 2013;57:2164-2170.

33. Willemse SB, Razavi-Shearer D, Zuure FR, et al. The estimated future disease burden of hepatitis $\mathrm{C}$ virus in the Netherlands with different treatment paradigms. Neth J Med. 2015;73:417-431.
34. Scalone L, Fagiuoli S, Ciampichini R, et al. The societal burden of chronic liver diseases: results from the COME study. BMJ Open Gastroenterol. 2015;2:e000025.

35. Vietri J, Prajapati G, El Khoury AC. The burden of hepatitis C in Europe from the patients' perspective: a survey in 5 countries. $B M C$ Gastroenterol. 2013;13:16.

36. Istat; Istituto nazionale di statistica [National institute of statistics; homepage]. http://www.istat.it/it/. Accessed July 4, 2017. Italian.

37. Mariano A, Scalia Tomba G, Tosti ME, Spada E, Mele A. Estimating the incidence, prevalence and clinical burden of hepatitis $\mathrm{C}$ over time in Italy. Scand J Infect Dis. 2009;41(9):689-699.

38. Ansaldi F, Bruzzone B, Salmaso S, et al. Different seroprevalence and molecular epidemiology patterns of hepatitis $\mathrm{C}$ virus infection in Italy. J Med Virol. 2005 Jul;76(3):327-332.
ClinicoEconomics and Outcomes Research

\section{Publish your work in this journal}

ClinicoEconomics and Outcomes Research is an international, peerreviewed open-access journal focusing on health technology assessment, pharmacoeconomics and outcomes research in the areas of diagnosis, medical devices, and clinical, surgical and pharmacological intervention. The economic impact of health policy and health systems
Submit your manuscript here: https://www.dovepress.com/clinicoeconomics-and-outcomes-research-journal

\section{Dovepress}

organization also constitute important areas of coverage. The manuscript management system is completely online and includes a very quick and fair peer-review system, which is all easy to use. Visit http://www.dovepress.com/testimonials.php to read real quotes from published authors. 